\title{
Epidemiology and Genotyping of Patients with Chronic Hepatitis B: Genotype Shifting Observed in Patients from Central Europe
}

\author{
ALFRED L. BISSINGER ${ }^{1,2}$, CHRISTOF FEHRLE ${ }^{1,3}$, CHRISTOPH R. WERNER ${ }^{1}$, ULRICH M. LAUER ${ }^{1}$, \\ NISAR P. MALEK ${ }^{1}$ and CHRISTOPH P. BERG ${ }^{{ }^{*}}$ \\ ${ }^{1}$ Medical Clinic, Department of Gastroenterology, Hepatology, and Infectiology \\ Medical University Hospital Tübingen, Tübingen, Germany \\ ${ }^{2}$ Institute of Tropical Medicine, Medical University Hospital Tübingen, Tübingen, Germany \\ ${ }^{3}$ Steinenberg Clinic, Department of Surgery, Reutlingen, Germany
}

Submitted 25 September 2014, revised 4 December 2014, accepted 5 December 2014

\begin{abstract}
Background: Knowledge on HBV prevalence and genotype distribution in Europe still is hampered by lack of coherent data sampling, small numbers of patients studied so far, and also modern times migration which influences both parameters in a quite dynamic manner. To find out whether HBV prevalence and genotype distribution has undergone any significant changes over the past decades, we have analyzed our cohort of HBV patients. Methods: Retrospective analysis of virological data and correlation with the epidemiological backgrounds of 408 chronically HBV-infected patients, followed in the year 2009 at Tübingen Virus Hepatitis Center, Germany. Results: A background of migration was found in more than $80 \%$ of our HBV patients, displaying an origin from 41 different countries. Analysis of the genotypes revealed that genotype A predominated only among patients from Central Europe with $55.8 \%$ while genotype D, known to be most common worldwide, was most prevalent in patients born in Eastern and Southern Europe, Central Asia and Middle East, exhibiting a range from $81 \%$ to $94 \%$. In Central Europe, genotype A was particularly seen in older patients as compared to genotype D that predominated in the younger patients. Conclusions: These data suggest that Central Europe is straight on its way to switch from genotype A to genotype D. One reason for this significant shift may be related to the ongoing European and global migration flow.
\end{abstract}

Ke y words: chronic hepatitis B, epidemiology, genotype, HBV, migration background

\section{Introduction}

Worldwide, over 360 million people suffer from a chronic course of hepatitis B virus (HBV) infection. Beyond that, more than 2 billion people are estimated to have experienced contact with HBV (World Health Organization, 2009). Due to the potential risk of developing liver cirrhosis or hepatocellular carcinoma, chronic hepatitis B constitutes a serious health burden (World Health Organization, 2009; Robert Koch Institut, 2013a).

Interestingly, great differences in $\mathrm{HBV}$ prevalence and in HBV genotypes are observed worldwide: in African and Asian countries, a high rate of HBV prevalence $(>8 \%)$ is found, whereas much lower rates $(<2 \%)$ are documented for European and Northern American countries (World Health Organization, 2009; Robert Koch Institut, 2013a). Furthermore, distinct regions exhibit a dominance of distinct HBV genotypes: in Central Europe and also for a long time in North Ame- rica countries, genotype A had been found to be predominant. In contrast, non A genotypes are predominant in the other world regions: genotypes $\mathrm{B}$ and $\mathrm{C}$ in Eastern and Southeastern Asia, genotype E in Western Africa. Furthermore, genotype D is spreading worldwide (Norder et al., 2004; Schaefer, 2005). Besides their epidemiological importance, HBV genotypes may also cause differences in the progression and the outcome of chronic hepatitis B (Schaefer, 2005; Lin and Kao, 2011; Araujo et al., 2011) and influence the choice of treatment regimes. In this respect, especially genotype A patients have been suggested to preferably benefit from the application of interferon $\alpha 2$ (Lin and Kao, 2011; Cornberg et al., 2011; European Association for the Study of the Liver, 2012; Flink et al., 2006).

One reason for low prevalence rates in Central Europe are recommendations from both the WHO and national organizations such as the STIKO (German Standing Committee on Vaccination) for immunization of children as early as in 1992 and 1995, respectively

* Corresponding author: C.P. Berg, Medical University Hospital Tübingen, Department of Gastroenterology, Hepatology, and Infectiology, Tübingen, Germany; e-mail: Christoph.Berg@med.uni-tuebingen.de 
(Robert Koch Institut, 2012). These resulted in significantly increasing rates of HBV vaccination already in children entering school in Germany (2001: 57.2\%, 2011: 86.2\%) (Robert Koch Institut, 2013a; 2013b). However, it is surprising that despite this highly successful vaccination program the prevalence of chronic hepatitis B in Germany hardly decreased in recent years and still remains at a fairly high rate of $0.6 \%$ (Thierfelder et al., 2001). Therefore, other reasons must contribute to this more or less steady state pattern of HBV prevalence in Germany.

To gain more insight in the epidemiology and the origin of chronic hepatitis B in Central Europe, as recently demanded by the German Robert Koch Institute (RKI) (Robert Koch Institut, 2013a), we performed a single center analysis in chronic hepatitis B infected patients, monitored 2009 at our Virus Hepatitis Center of the University Hospital Tübingen, Germany.

\section{Experimental}

\section{Materials and Methods}

In the year 2009, a total of 408 patients presented with chronic hepatitis B infection at our Virus Hepatitis Center at the University Hospital Tübingen, Germany. All 408 study cohort patients were analyzed retrospectively with respect to virological, epidemiological and geographical parameters. Data were collected after the respective outpatient contact using the patient files.

All countries of birth were geographically classified in 7 different areas: Central Europe (encompassing Germany, Poland, and the Czech Republic; please note: other Central European countries could not be taken into account due to a lack of patients from there in our study cohort), Southern Europe, Eastern Europe with Russia, Middle East with Turkey, Central Asia, Eastern and Southeastern Asia, and Africa.

In our study cohort, treatment-naïve hepatitis B viral load could be assessed retrospectively in 318 patients using the patient files. HBV genotypes could be determined retrospectively in 276 patients using the patient files. The genotyping was done either by genome sequencing or by DNA Line Probe Assay (INNO-LiPA HBV Genotyping, Innogenetics, Hannover, Germany) (Guirgis et al., 2010). As expected, genotype analysis did not yield results in cases with very low viral loads $(<500 \mathrm{IU} / \mathrm{mL})$.

To obtain evidence of age-related phenomena as a surrogate for changes over time, the 276 genotyped study cohort patients were assigned to three age groups: (i) $<30$ years $(n=91)$, (ii) $30-45$ years $(n=100)$, (iii) $>45$ years $(\mathrm{n}=85)$, respectively.

The non-parametric Mann-Whitney-Wilcoxon U test was performed to statistically analyze the age distri- bution in different patient groups. $P$-values $<0.05$ were considered to be statistically significant.

Anonymised data were collected retrospectively, no parameter was determined in addition to the standard outpatient setting. According to the local ethics committee of the University Hospital Tübingen, Germany, no ethics approval is required for this retrospective analysis with cross sectional design.

\section{Results}

All 408 study patients, that presented at our Virus Hepatitis Center in the year 2009, were characterized as shown in Table I. Treatment-naïve hepatitis B viral load could be assessed retrospectively in 318 patients with a median viral load in $\mathrm{HBeAg}$-positive patients of $1 \times 10^{6} \mathrm{IU} / \mathrm{ml}$ and a median viral load in HBeAgnegative patients of $2 \times 10^{3} \mathrm{IU} / \mathrm{ml}$.

Table I

Characteristics of Tübingen chronic hepatitis B study cohort.

\begin{tabular}{|l|l|}
\hline Tübingen study cohort & \\
\hline Evaluated patients, total & 408 \\
number [n]: & $255(62.5 \%)$ \\
Male [n]: & $153(37.5 \%)$ \\
Female [n]: & \\
\hline Age at first contact to Tübingen & \\
Virus Hepatitis Center & median 37.0 (range 15-74) \\
All patients [years]: & median 37.0 (range 15-74) \\
Male [years]: & median 36.5 (range 16-71) \\
Female [years]: & 400 \\
\hline Country of birth, assignable [n]: & 276 \\
\hline HBV genotype, determinable [n]: & 276 \\
\hline HBV genotype \& country of birth, & \\
definable [n]: & 269 \\
\hline
\end{tabular}

In our Tübingen study cohort of chronically HBV infected patients, countries of birth could be identified in 400 of the 408 patients. On this basis, 41 different countries of origin were identified and assigned to seven major geographic areas. Individual countries together with the respective number of patients and the assignment to our classified geographic areas are given in detail in Table II. Of note, $81 \%$ of our HBV patients were born outside of Germany. Additionally, also 18 of the 76 patients born in Germany were found to have a background of migration due to the foreign origin of their parents (second generation immigrants). Thus, an overall migration background was identified in more than $85 \%$ of our Tübingen study cohort patients.

In 276 of the 408 patients (67.6\%) the HBV genotype could be identified respectively. Genotype D was found to be most frequent, genotype A was found to be the second most frequent one. In detail, the distribu- 
Table II

Geographic origin of patients from Tübingen chronic hepatitis B study cohort [ $n=400]$

\begin{tabular}{|c|c|c|c|}
\hline Geographic groups & Countries of birth & Patients $[\mathrm{n}]$ & Percentage $[>1 \%]$ \\
\hline \multirow[t]{3}{*}{ Central Europe $[\mathrm{n}=85]$} & Germany & 76 & 19.0 \\
\hline & Poland & 8 & 2.0 \\
\hline & Czech Republic & 1 & \\
\hline \multirow[t]{7}{*}{ Southern Europe $[n=82]$} & Greece & 24 & 6.0 \\
\hline & Italy & 22 & 5.5 \\
\hline & Kosovo & 14 & 3.5 \\
\hline & Croatia & 9 & 2.25 \\
\hline & Bosnia & 6 & 1.5 \\
\hline & Serbia & 4 & \\
\hline & Albania & 3 & \\
\hline \multirow[t]{6}{*}{ Eastern Europe with Russia [n=45] } & Russia & 20 & 5.0 \\
\hline & Romania & 16 & 4.0 \\
\hline & Ukraine & 3 & \\
\hline & Byelorussia & 2 & \\
\hline & Georgia & 2 & \\
\hline & Moldova & 2 & \\
\hline \multirow[t]{5}{*}{ Middle East with Turkey [n=81] } & Turkey & 77 & 19.25 \\
\hline & Iran & 1 & \\
\hline & Lebanon & 1 & \\
\hline & Palestine & 1 & \\
\hline & Syria & 1 & \\
\hline \multirow[t]{4}{*}{ Central Asia $[n=60]$} & Kazakhstan & 41 & 10.25 \\
\hline & Kyrgyzstan & 9 & 2.25 \\
\hline & Uzbekistan & 7 & 1.75 \\
\hline & Tajikistan & 3 & \\
\hline \multirow[t]{8}{*}{ Eastern and Southeastern Asia $[\mathrm{n}=31]$} & Vietnam & 13 & 3.25 \\
\hline & China & 9 & 2.25 \\
\hline & Thailand & 4 & \\
\hline & Malaysia & 1 & \\
\hline & Philippines & 1 & \\
\hline & South Korea & 1 & \\
\hline & Sri Lanka & 1 & \\
\hline & Taiwan & 1 & \\
\hline \multirow[t]{8}{*}{ Africa $[n=16]$} & Ghana & 5 & 1.25 \\
\hline & Cameroon & 3 & \\
\hline & Ethiopia & 2 & \\
\hline & Nigeria & 2 & \\
\hline & Congo & 1 & \\
\hline & Sierra Leone & 1 & \\
\hline & Somalia & 1 & \\
\hline & Togo & 1 & \\
\hline
\end{tabular}

tion of the HBV genotypes in our cohort is shown in Table III. In the remaining 132 cases, the genotype was not determinable due to a low viral load.

In 269 of the 408 patients both origin (country of birth) as well as the respective genotype could be determined (Table IV). Our results demonstrate that the distribution of HBV genotypes is strictly related to the typology of immigration and goes along with the pattern of geographic origin. This is underlined by our finding that only in Central European patients genotype A was found to predominate (55.8\%), whereas genotype D was second most frequent (38.5\%). These 
Table III

Distribution of HBV genotypes in the Tübingen study cohort $[\mathrm{n}=276]$

\begin{tabular}{|c|r|r|c|}
\hline \multirow{2}{*}{ Genotype: } & \multicolumn{2}{|c|}{ Patients } & \multirow{2}{*}{ Age [median, range] } \\
\cline { 2 - 3 } & {$[\mathrm{n}]$} & \multicolumn{1}{c|}{$[\%]$} & \\
\hline A & 55 & $19.9 \%$ & 39 years $(15-67$ years $)$ \\
\hline B & 7 & $2.5 \%$ & 43 years $(16-52$ years $)$ \\
\hline C & 18 & $6.5 \%$ & 33 years $(18-47$ years $)$ \\
\hline D & 188 & $68.1 \%$ & 35 years $(15-74$ years $)$ \\
\hline E & 6 & $2.2 \%$ & 31 years $(23-47$ years $)$ \\
\hline F & 1 & $0.4 \%$ & n. d. \\
\hline G & 0 & $0 \%$ & n. d. \\
\hline H & 1 & $0.4 \%$ & n. d. \\
\hline
\end{tabular}

n.d.: not determined type $D[n=20]$ (33 years, range $21-74$ years) did not differ much from the median age of non Central European patients with genotype $D[n=168]$ (35.5 years, range 15-64 years) (Fig. 1). Patients born in Eastern Europe with Russia, Southern Europe, Central Asia, and Middle East with Turkey, were found to be predominantly infected with $\mathrm{HBV}$ genotype $\mathrm{D}$, patients born in Eastern and Southeastern Asia were predominantly infected with $\mathrm{HBV}$ genotype $\mathrm{C}$, and patients born in Africa were predominantly infected with $\mathrm{HBV}$ genotype E, as shown in Table IV.

In the next step of our data analysis, a more refined examination was conducted in our patients exhibiting the two most dominant genotypes $A(n=55)$ and $\mathrm{D}(\mathrm{n}=188)$. We specifically focused on the question

Table IV

Correlation of country of birth and HBV genotype $[n=269]$. The regions were assigned as shown in Table II.

\begin{tabular}{|l|c|c|c|}
\hline \multicolumn{1}{|c|}{ Region of birth } & Patients [n] & Most frequent genotype [n, \%] & Second most frequent genotype [n, \%] \\
\hline Central Europe & 52 & A 29 [55.8\%] & D 20 [38.5\%] \\
\hline Eastern Europe / Russia & 37 & D 30 [81.1\%] & A 7 [18.9\%] \\
\hline Southern Europe & 53 & D $45[84.9 \%]$ & A $713.2 \%]$ \\
\hline Central Asia & 41 & D 37 [90.2\%] $[9.7 \%]$ \\
\hline Middle East / Turkey & 52 & D 49 [94.2\%] & A 2 [3.8\%] \\
\hline Eastern / Southeastern Asia & 25 & C 16 [64.0\%] & B 4 [16.0\%] \\
\hline Africa & 9 & E 6 $[66.7 \%]$ & A $[22.2 \%]$ \\
\hline
\end{tabular}

genotype A patients from Central Europe [n=29] (Table IV) exhibited a median age of 45 years (range 16-62 years) whereas genotype A patients with non Central European origin $[\mathrm{n}=26]$ displayed a median age of only 30 years (range 15-67 years) (Fig. 1). Thus, Central European patients with genotype A were found to be significantly older than genotype A patients with a non Central European origin $(\mathrm{p}=0.011)$. In contrast, the median age of Central European patients with geno-

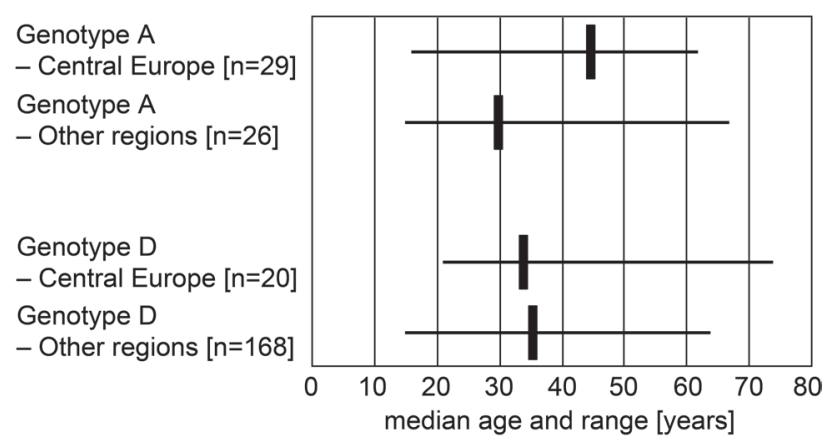

Fig. 1. Correlation of median age and origin of birth in patients with HBV genotypes A $[n=55]$ and D $[n=188]$. Genotype A patients born in Central Europe were found to be significantly older then genotype A patients born in other regions $(\mathrm{p}=0.011)$. In contrast, genotype D patients showed no difference in the median age concerning their region of origin. Other genotypes are not depicted because of low prevalences. whether an "HBV genotype shifting" might have taken place over the last two decades potentially resulting from HBV vaccination programs being installed in Central European countries since the mid-1990s and from the ongoing European and global migration flow. For this purpose, we first assigned all genotyped study patients $(n=276)$ to our three age groups and the genotype A patients could be assigned as follows: (i) age group $<30$ years: 15 patients (16.5\% of all genotyped patients $<30$ years), (ii) age group 30-45 years: 18 patients ( $18.0 \%$ of all genotyped patients $30-45$ years), (iii) age group $>45$ years: 22 patients (25.9\% of all genotyped patients $>45$ years).

We then also compared the frequency of genotypes $\mathrm{A}$ and $\mathrm{D}$ in patients born in Central and non Central European countries with respect to the assignment to our three age groups (Fig. 2). In Central European patients, genotype A patients $(n=29)$ were assigned as follows: (i) age group $<30$ years: 3 patients $(20.0 \%$ of 15 patients), (ii) age group 30-45 years: 11 patients (68.7\% of 16 patients), (iii) age group $>45$ years: 15 patients ( $71.4 \%$ of 21 patients) (Fig. 2, grey bars). In the non Central European genotype A patients $(n=26)$, age dependent distribution was: (i) age group $<30$ years: 12 patients ( $15.8 \%$ of 76 patients), (ii) age group $30-45$ years: 7 patients ( $8.3 \%$ of 84 patients), (iii) age 


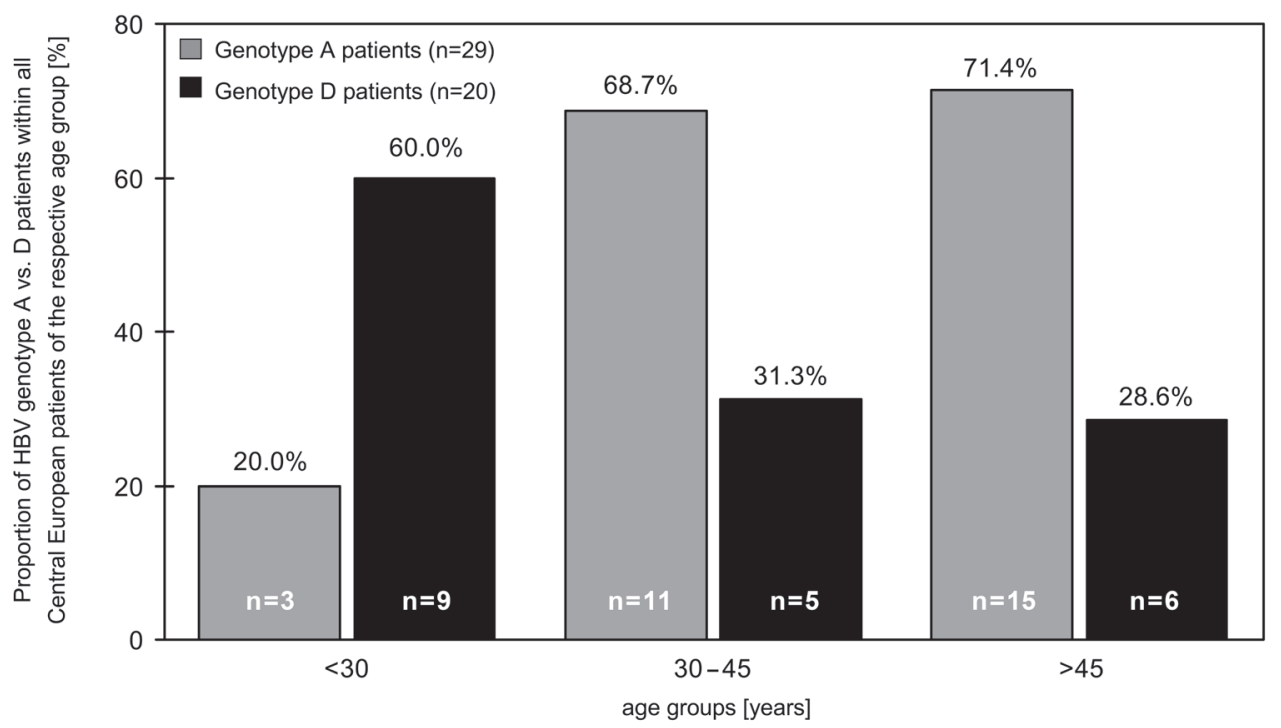

Fig. 2. Genotype shift in 52 patients born in Central Europe from genotype A to genotype D. Age-dependent decrease of the proportion of HBV genotype A [ $n=29]$ versus increase of the proportion of HBV genotype D [ $n=20]$. The remaining 3 of the 52 patients had other genotypes and were younger than 30 years. Interestingly, an over proportional amount of Central European genotype A patients (in the range of $70 \%$ ) was seen in the patients $\geq 30$ years of age.

group $>45$ years: 7 patients $(11.1 \%$ of 63 patients) (data not depicted in Fig. 2).

Conversely to this decline in the proportion of genotype A in Central European patients with decreasing age, genotype $\mathrm{D}$ gained importance in patients with decreasing age born in Central Europe as demonstrated by the sharp rise from $28.6 \%$ ( $>45$ years) and $31.3 \%$ (45-30 years) to $60.0 \%$ (<30 years) (Fig. 2, black bars). Beyond that, also other genotypes seem to come up in the age group $<30$ years: two male patients with genotype $\mathrm{C}$ and one male patient with genotype $\mathrm{F}$ were identified in this patient group. Taken together, these data indicate a significant genotype shifting in Central European patients with chronic hepatitis B.

\section{Discussion}

We present here the data of our single center analysis on a large cohort of chronic HBV infected patients who presented in 2009 at our Virus Hepatitis Center at the University Hospital Tübingen, Germany.

Importantly, our monocentric Tübingen data first of all reflect the well-documented migration flow into many developed countries in Central Europe and elsewhere, especially coming from high endemic areas for HBV (Robert Koch Institut, 2013a): more than 80\% of our patients were identified as foreigners and more than $85 \%$ exhibited a background of migration (first plus second generation immigrants). As compared with two other recent German studies (analyzing either 250 patients in the German Ruhr area (2001-2006) (Niederau, 2007) or 1,535 patients with a viral load
$>2,000 \mathrm{IU} / \mathrm{ml}$ (2004-2007) (Fischer et al., 2012)), the migration background has increased considerably from 63.1\% (Fischer et al., 2012) and 67.6\% (Niederau, 2007) to our Tübingen study cohort rate of now more than 85\% (Table II). Especially the number of immigrants from the former Soviet Union and its satellite states increased remarkably from low levels of $11.2 \%$ (Niederau, 2007) and $17.2 \%$ (Fischer et al., 2012) to a percentage as high as $37.5 \%$ in our study cohort (Table II). Concomitantly, the number of patients with a Turkish background decreased from 34.8\% (Niederau, 2007) and $22.4 \%$ (Fischer et al., 2012) to $19.3 \%$ in our study cohort (Table II).

Our data further imply that in most instances HBV infection has been acquired in the respective native countries of the immigrants. Thus, genotype $\mathrm{D}$, being known as the most frequent genotype worldwide (Norder et al., 2004), was also found to be highly prominent in our Tübingen patients, representing $68.1 \%$ of our study cohort (Table III). Genotype A was present in the subgroup with Central European origin in a high percentage (55.8\%), while patients born in Eastern or Southeastern Asia mostly exhibited genotypes B or C. In the patients born in Africa, genotype $\mathrm{E}$ predominated (Table IV). These findings match similar data being obtained in the respective countries and regions (Norder et al., 2004; Schaefer, 2005).

When correlating the distribution of genotypes A and D with different age groups of our study cohort, an interesting age-dependent shift was observed: genotype A patients born in Central Europe were significantly older than the respective genotype A patients born in other regions (Fig. 1). Additionally, for the 
whole study group a decrease in the proportion of genotype A patients was observed age-related so that more and more younger patients had to be identified as "non genotype A" patients. This could be referred to the fact, that genotype A was overrepresented in older patients born in Central Europe and thus the genotype A predominated only in the patients born in Central Europe in the age groups of 30 years and older (Fig. 2, grey bars to the right).

An overall decline in HBV prevalence in the last decades and thus specifically also in genotype A prevalence is supposed to be due to the introduction of perioperative HBV diagnostics and the availability of a first vaccine in 1982 which later on led to the introduction of routine HBsAg screening in pregnancy in 1994 in Germany with consecutive active and passive immunization of infants (Mutterschafts-Richtlinien, 2012), and due to the general recommendation for HBV immunization of children in Germany in 1995 (Robert Koch Institut, 2012) (in response to the WHO resolution imposed in 1992).

Our data regarding the median age as well as the proportion of the distinct genotype subgroups provide some evidence for the hypothesis that young Central European patients are less frequently infected with genotype $\mathrm{A}$. Thus, our data indicate that the autochthonous European genotype A infection probably will be displaced over time, while genotype D concurrently will close this gap. In younger Central European patients, a dominance of genotype D already is in place (Fig. 2, black bar to the left). As an obvious cause, this phenomenon seems to be due to (i) European HBV specific measures (diagnostics and vaccinations), sharply cutting down all autochthonous cases including the predominant genotype $\mathrm{A}$, and due to (ii) the spread of imported genotypes other than A, reflecting the opening of Central European societies in an increasingly globalized world.

These data point out that the proportion of genotype A patients in our Tübingen study cohort might be constantly decreasing over time, irrespective of the origin of birth of our study patients. Thus, the proportion of genotype A patients was found to have decreased from a high level in the Central European patients in an above average manner (Fig. 2, grey bars), whereas in the non Central European patients the proportion of genotype A varied only little and remained at low rates (in the range of about 10\%).

A similar replacement of the formerly most frequent genotype A by genotypes B and C already can be observed in Northern American countries, there being fueled mainly by the considerable migration inflow from Asian countries (exhibiting strong association with ethnicity), as recently published by Congly et al., (2013). Thus, the global migratory flow may sig- nificantly modify also the Central European geographic distribution of HBV genotypes in the near future. Taking into account, that antiviral therapy with pegylated interferon $\alpha 2$ is most promising in patients with genotype A infection (Lin and Kao, 2011; Cornberg et al., 2011; European Association for the Study of the Liver, 2012), the assumed shift of genotypes in Central Europe will possibly influence the proportion of interferon usage in patients with chronic hepatitis B infection.

However, the specific contribution of the diverse routes of HBV transmission for this shifting towards non A genotypes remain unclear. One possible explanation could be that infections with non A genotype hepatitis B viruses of unvaccinated take place preferably in adolescence (due to changing sexual and travel behaviors). A second explanation could be a transmission already in infancy (due to contacts with chronically infected playfellows, e. g. originating from abroad). A third way is the vertical mother to child transmission especially in cases born in Germany with a background of familial migration. In this context, it also has to be noted, that the rate of chronicity of HBV infections decreases with increasing age (World Health Organization, 2009). Thus, it is evident that a consequent and timely immunization of children and adult migrants as well as especially the treatment of highly viremic women in pregnancy (Cornberg et al., 2011; European Association for the Study of the Liver, 2012) is of utmost importance to achieve an assured closing of these routes of HBV transmission. Screening for hepatitis B should be carried out even more consistently, particularly aiming at risk groups such as individuals with migration background, as recommended by the German Standing Committee on Vaccination, STIKO (Robert Koch Institut, 2012). In seronegative and susceptible individuals HBV immunization should be propagated consequently.

\section{Competing Interest}

The authors declare that they do not have anything to disclose regarding funding or conflict of interest with respect to this manuscript.

\section{Authors' Contributions}

ALB was the treating physician, ALB and CF collected the data. $A L B$ and $\mathrm{CPB}$ designed the study, analyzed the research quality and wrote the manuscript. CRW, UML and NPM critically revised the manuscript for important intellectual content. All authors read and approved the final manuscript.

\section{Literature}

Araujo N.M., R. Waizbort and A. Kay. 2011. Hepatitis B virus infection from an evolutionary point of view: how viral, host, and environmental factors shape genotypes and subgenotypes. Infect. Genet. Evol. 11: 1199-1207. 
Congly S.E., P. Wong, S.A. Al-Busafi, K. Doucette, S.K. Fung, P. Ghali, K. Fonseca, R.P. Myers, C. Osiowy and C.S. Coffin. 2013. Characterization of hepatitis $\mathrm{B}$ virus genotypes and quantitative hepatitis B surface antigen titres in North American tertiary referral liver centres. Liver Int. 33: 1363-1369.

Cornberg M., U. Protzer, J. Petersen, H. Wedemeyer, T. Berg, W. Jilg, A. Erhardt, S. Wirth, C. Sarrazin, M.M. Dollinger and others. 2011. Aktualisierung der S3-Leitlinie zur Prophylaxe, Diagnostik und Therapie der Hepatitis-B-Virusinfektion, AWMF-Register-Nr.: 021/011. Z. Gastroenterol. 49: 871-930.

European Association for the Study of the Liver. 2012. EASL Clinical Practice Guidelines: Management of chronic hepatitis B virus infection. J. Hepatol. 57: 167-185.

Fischer C., S. Mauss E. Zehnter, B. Bokemeyer, R. Heyne and D. Hüppe. 2012. Epidemiology and clinical characteristics of patients with chronic hepatitis B (CHB) in Germany - Results of a nationwide cross-sectional study. Z. Gastroenterol. 50: 22-29.

Flink H.J., M. van Zonneveld, B.E. Hansen, R.A. de Man, S.W. Schalm and H.L. Janssen. 2006. Treatment with Peg-interferon alpha-2b for HBeAg-positive chronic hepatitis B: HBsAg loss is associated with HBV genotype. Am. J. Gastroenterol. 101: 297-303. Guirgis B.S., R.O. Abbas and H.M. Azzazy. 2010. Hepatitis B virus genotyping: current methods and clinical implications. Int. J. Infect. Dis. 14: e941-953.

Lin C.L. and J.H. Kao. 2011. The clinical implications of hepatitis B virus genotype: Recent advances. J. Gastroenterol. Hepatol. 26s1: 123-130.

Mutterschafts-Richtlinien. 2012. Richtlinien des Bundesausschusses der Ärzte und Krankenkassen über die ärztliche Betreuung während der Schwangerschaft und nach der Entbindung. Bundesanzeiger. http://www.g-ba.de/downloads/62-492-665/Mu-RL_201210-18.pdf. Accessed 11 Jan 2013.

Niederau C. 2007. Epidemiologie der Hepatitis-B-Virusinfektionen in Deutschland. Med. Klin. 102: 351-357.

Norder H., A.M. Couroucé, P. Coursaget, J.M. Echevarria, S.D. Lee, I.K. Mushahwar, B.H. Robertson, S. Locarnini and L.O. Magnius. 2004. Genetic diversity of Hepatitis B virus strains derived worldwide: genotypes, subgenotypes, and HBsAg subtypes. Intervirology 47: 289-309.

Robert Koch Institut (RKI). 2012. Mitteilung der Ständigen Impfkommission am Robert Koch Institut (RKI). Empfehlungen der Ständigen Impfkommission (STIKO) am Robert Koch Institut, Stand Juli 2012. Epidemiol. Bulletin 30: 283-310.

Robert Koch Institut (RKI). 2013a. Virushepatitis B und D im Jahr 2012. Epidemiol. Bulletin 29: 259-269.

Robert Koch Institut (RKI). 2013b. Impfquoten bei der Schuleingangsuntersuchung in Deutschland 2011. Epidemiol. Bulletin 16: $129-133$.

Schaefer S. 2005. Hepatitis B virus: significance of genotypes. J. Viral. Hepatitis 12: 111-124.

Thierfelder W., W. Hellenbrand, H. Meisel, E. Schreier and R. Dortschy. 2001. Prevalence of markers for hepatitis A, B and C in the German population. Results of the German National Health Interview and Examination Survey 1998. Eur. J. Epidemiol. 17: 429-435.

World Health Organization (WHO). 2009. Weekly epidemiological record No. 40. 84:405-20. http://www.who.int/wer/2009/ wer8440. pdf 
